\title{
Association between circulating levels of heat-shock protein 27 and aggressive periodontitis
}

\author{
Frank Kaiser ${ }^{1} \cdot$ Nikos Donos $^{2} \cdot$ Brian Henderson $^{1} \cdot$ Rajesh Alagarswamy $^{1} \cdot$ George Pelekos $^{3} \cdot$ David Boniface $^{4}$. \\ Luigi Nibali ${ }^{2}$
}

Received: 22 January 2018 / Revised: 2 March 2018 / Accepted: 9 March 2018 / Published online: 15 May 2018

(C) The Author(s) 2018

\begin{abstract}
Heat-shock protein (Hsp) 27 is a major intracellular molecular chaperone and controller of intracellular responses to inflammatory signals. In the extracellular space, recombinant Hsp27 has been described to exert anti-inflammatory activities. The aim of this study was to assess the association between circulating levels of Hsp27 and different types of periodontitis. Pro- and antiinflammatory cytokines and the stress proteins Hsp27 and Hsp60 with proposed anti- and pro-inflammatory properties, respectively, were measured by two-site ELISA in the serum of patients with aggressive periodontitis ( $\mathrm{AgP}, n=30)$, chronic periodontitis $(\mathrm{CP}, n=29)$ and periodontally healthy controls $(\mathrm{H}, n=28)$. Furthermore, Hsp27 and Hsp60 levels were also measured longitudinally in $12 \mathrm{AgP}$ patients at 6 time points up to 3 months after treatment. AgP patients had lower levels of Hsp27 compared to CP patients and healthy subjects (adjusted one-way ANOVA, $p<0.001$, followed by post hoc Tukey HSD comparisons), while no differences in levels of Hsp60 or cytokines between the three groups were detected. In CP patients and $\mathrm{H}$ subjects, the systemic Hsp27 levels correlated with $\operatorname{Hsp60}(r=0.43, p<0.001 ; r=0.59, p<0.001$, respectively) and with proinflammatory cytokines TNF- $\alpha(r=0.48, p<0.001 ; r=0.55, p<0.001$, respectively $)$ and IL-6 $(r=0.44, p<0.01)$. However, no such correlations were detected in $\mathrm{AgP}$ cases. No consistent temporal patterns of changes of Hsp27 concentration were detected across AgP patients following periodontal treatment. This study provides the first evidence that Hsp27 may be differentially expressed and regulated in $\mathrm{AgP}$ patients as compared with $\mathrm{CP}$ patients and healthy individuals.
\end{abstract}

Keywords Periodontitis $\cdot$ Stress proteins $\cdot$ Hsp27 $\cdot$ Inflammation $\cdot$ Cytokines

\section{Introduction}

The periodontal diseases are the world's most common chronic inflammatory diseases (Eke et al. 2012) and are currently subdivided into a number of diagnostic categories (Armitage 2004). Of these, the two principal forms of

Luigi Nibali

1.nibali@qmul.ac.uk

1 Department of Microbial Diseases, Eastman Dental Institute, University College London, London, UK

2 Centre for Immunobiology and Regenerative Medicine and Centre for Oral Clinical Research, Institute of Dentistry, Barts and the London School of Medicine and Dentistry, Queen Mary University London, Turner Street E1 2AD, London, UK

3 Faculty of Dentistry, The University of Hong Kong, Pokfulam, Hong Kong

4 Biostatistics Unit, Eastman Dental Institute, University College London, London, UK periodontitis, chronic (CP) and aggressive periodontitis $(\mathrm{AgP})$, have been suggested to differ in clinical appearance and disease progression (Armitage and Cullinan 2010). However, objective clinical measures have thus far failed to discriminate between these two perceived conditions (Frydman and Simonian 2011). For example, these gingival diseases cannot be histologically (Smith et al. 2010) or microbiologically (Armitage 2010) discriminated, and analysis of gene expression profiles (Kebschull et al. 2013) or measures of systemic inflammation (Cairo et al. 2010) have not proved diagnostically discriminatory.

There is a very large number of proposed diagnostic and prognostic biomarkers, although very few of them have bridged the translational gap in inflammatory diseases (Mischak et al. 2012). One of the most intriguing groups of potential biomarkers are cell stress proteins. These include various families of protein-folding proteins known as molecular chaperones and protein-folding catalysts whose intracellular levels have mostly been reported to increase in stressed cells 
(Saibil 2013). However, several studies have observed a decrease in intracellular Hsp70 and Hsp90 levels in monocytes and polymorphonuclear cells, along with a pattern of early extracellular induction in acute conditions like sepsis (Vardas et al. 2014; Papadopoulos et al. 2017; Spanaki et al. 2018). It is rapidly becoming established that these proteins are pivotal controllers of cellular proteostasis, the network of competing and integrated biological pathways that controls protein biogenesis, folding, trafficking and degradation. Defective proteostasis is associated with cell and tissue pathology (Jovaisaite et al. 2014; Wang et al. 2014). It has been recognised since the 1970s that cell stress proteins can be secreted by cells and can enter into the circulation (Henderson and Pockley 2005). In more recent years, cell stress proteins have been proposed as useful biomarkers (Henderson and Pockley 2012). For example, Hsp72 levels were able to discriminate sepsis from systemic inflammatory response syndrome (SIRS) and furthermore, they were strong predictors of mortality (Vardas et al. 2017). Unlike some other biomarkers, cell stress proteins exert potent intercellular signalling activities with properties resembling both pro- or anti-inflammatory cytokines (Henderson and Pockley 2010; Pockley and Henderson 2018).

In a previous trial, our group assayed plasma obtained from patients with chronic periodontitis and control subjects for systemic levels of a number of cell stress proteins, Hsp10, Hsp60 and BiP (Henderson and Pockley 2010). Levels of Hsp10 and BiP were significantly lower in the blood of patients compared with controls, while Hsp60 levels were similar in both groups. Effective treatment of periodontitis was associated with a significant increase in Hsp10 levels to those found in controls and a lesser increase in BiP levels with no change in Hsp60. This initial evidence shows the potential importance of circulating cell stress proteins in periodontitis and its response to treatment.

In this study, we concentrated on another cell stress protein, the myeloid cell-modulating cell stress protein Hsp27, which has been described to exert anti-inflammatory activities (De et al. 2000; Laudanski et al. 2007). The main outcome was Hsp27 serum concentration and the null hypothesis was that systemic Hsp27 and Hsp60 levels do not vary in AgP and $\mathrm{CP}$, as compared to healthy subjects. Furthermore, we explored associations between Hsp27 and Hsp60 and key inflammatory and anti-inflammatory cytokines as well as longitudinal changes in Hsp27 following periodontal treatment in AgP.

\section{Methods}

\section{Subject selection, clinical evaluation and periodontal treatment}

The analyses described here consisted of a case-control and a treatment study. Both studies were reviewed and approved by the UCL/UCLH joint ethics committee (references 05/Q0502/
84 and $07 / \mathrm{H} 0713 / 74$ ), and suitable individuals referred for care at the Eastman Dental Hospital gave written informed consent to take part. All participants were of Caucasian origin. Exclusion criteria for both studies were presence of other chronic oral conditions as assessed by the examining clinician: pregnancy; reported history of medical conditions or concomitant systemic medications; intake of anti-inflammatory drugs or antibiotics within 3 months; known infectious diseases and previous periodontal therapy within 12 months. At the baseline visit, the patients' height, weight and waist circumference were taken and BMI calculated. A single calibrated examiner measured full-mouth probing pocket depth (PPD), clinical attachment loss (CAL) and full-mouth bleeding on probing score (FMBS) at six sites per tooth as previously described (Guerrero et al. 2005). Repeated measurements of 10 non-study subjects (with at least $15 \mathrm{~min}$ separation) showed 98\% intra-examiner repeatability within $2 \mathrm{~mm}$ for PPD.

The case-control study consisted of a total of 87 consecutive ethnically Caucasian subjects drawn from a larger casecontrol study, based on the following characteristics:

- Periodontally healthy controls $(\mathrm{H}, n=28)$ with $\mathrm{PPD} \leq 4 \mathrm{~mm}$ and FMBS $<20 \%$

- Chronic periodontitis (CP, $n=29)$, with at least 10 sites with PPD $>4 \mathrm{~mm}$

- Aggressive periodontitis (AgP, either localised or generalised, $n=30$ ), with PPD and CAL $\geq 6 \mathrm{~mm}$ and bleeding on probing in at least three sites in different teeth

Periodontitis patients were diagnosed with $\mathrm{AgP}$ based on self-report of familial aggregation and systemic health and on rapid progression evidenced by either age at diagnosis $<45$ years old or radiographic evidence of bone loss $>1 \mathrm{~mm}$ in at least two non-adjacent sites within a 1-year period (Mombelli et al. 2002).

The treatment study included $12 \mathrm{AgP}$ patients (diagnosed as above) less than 45 years old. All treatment sessions were performed by a single qualified periodontist as described before (Nibali et al. 2013). Briefly, after a baseline visit, fullmouth non-surgical periodontal therapy (NSPT) was performed under local anaesthesia on day 14, and follow-up oral hygiene instructions were provided. Patients were reassessed an average of 30 days after NSPT. On day 70, periodontal surgical treatment (open-flap debridement, OFD) was performed under local anaesthesia in the worst affected quadrant (residual $>5 \mathrm{~mm}$ PPDs with bleeding on probing). Fullthickness muco-periosteal flaps were elevated, granulation tissue and subgingival debridement and, if required, localised non-supporting bone (osteoplasty) removed, and the flaps were readapted and sutured. Patients were seen for followups and blood samples taken on day 1, 7, 30, 60 and 90 after OFD surgery. 


\section{Blood sampling}

Blood samples were collected at the baseline visit for both investigations. For the intervention study, blood samples were additionally collected at all follow-up appointments. All patients had been fasting for $6 \mathrm{~h}$ prior to blood sampling on all visits. Blood was collected by venipuncture from the antecubital vein and serum was immediately separated by centrifugation. Serum samples were kept frozen at $-80{ }^{\circ} \mathrm{C}$ until the analyses were performed.

\section{Hsp27 measurement}

Hsp27 in serum was measured using an in-house-developed two-site enzyme-linked immunosorbent assay (ELISA). Briefly, 96-well plates (Immuno MaxiSorp, Nunc) were coated with a mouse monoclonal anti-HSP27 antibody (clone $2 \mathrm{~A} 5$, ATGen) at $1 \mu \mathrm{g} / \mathrm{ml}$ in coating buffer $(50 \mathrm{mM}$ carbonate-bicarbonate buffer, $\mathrm{pH} 9.6$ ) overnight at $4{ }^{\circ} \mathrm{C}$ (see Fig. 1). Plates were washed with wash buffer (PBS, $0.05 \%$ Tween-20), and non-specific binding sites were blocked by incubation with $2 \%(w / v)$ bovine serum albumin (BSA Chromatopur Immunoassay Grade, MP Biomedicals) in PBS for $1 \mathrm{~h}$ at room temperature. After washing, human recombinant Hsp27 protein (ATgen; 0-200 ng/ml) or dilutions (PBS) of serum samples and controls were added and incubated for $2 \mathrm{~h}$ at room temperature. Plates were washed extensively with wash buffer and incubated for $2 \mathrm{~h}$ at room temperature with a goat polyclonal anti-Hsp27 antibody (C-20, Santa Cruz; $1 \mu \mathrm{g} / \mathrm{ml}$ in $0.5 \%$ BSA/PBS). After

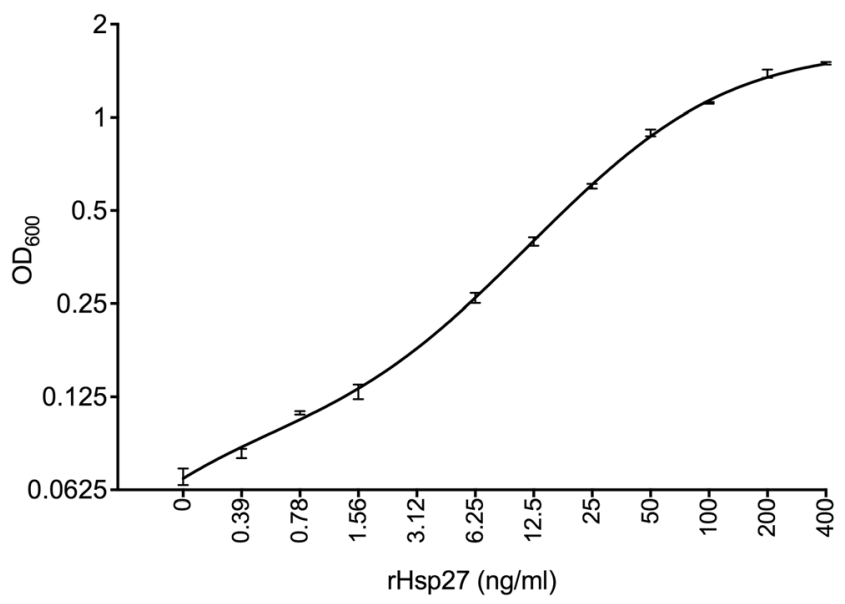

Fig. 1 Evaluation of the Hsp27 immunoassay (ELISA). The graph, a representative standard curve of the Hsp27 ELISA assay, shows the measurement of serial dilutions (1:2 in PBS) of recombinant Hsp27 starting at a concentration of $400 \mathrm{ng} / \mathrm{ml}$. Input $\mathrm{rHsp} 27$ concentrations $(\mathrm{ng} / \mathrm{ml})$ are plotted versus optical density $\left(\mathrm{OD}_{600}\right)$ after assay development, with both axes on $\log _{2}$ scale. Error bars show the standard deviation of triplicate sample measurements washing, bound goat anti-hsp27 antibody was detected by incubation with HRP-conjugated donkey polyclonal antigoat IgG (Santa Cruz ssc-2304, mouse and human adsorbed, $40 \mathrm{ng} / \mathrm{ml}$ in $0.5 \%$ BSA in wash buffer) at room temperature for $45 \mathrm{~min}$. Binding of conjugated antibody was detected using TMB substrate (affymetrix/eBioscience), and the reaction was stopped by adding $2 \mathrm{~N} \mathrm{H}_{2} \mathrm{SO}_{4}$. Absorbance at $450 \mathrm{~nm}$, using a $570-\mathrm{nm}$ reference wavelength, was determined with a plate reader (MRX II, Dynex). Cytokine concentrations were calculated by the plate reader software (Revelation, Dynex). Each serum sample was assayed in triplicate. The assay was highly specific for Hsp27 and showed no cross-reactivity with recombinant human Hsp10, Hsp60, or Hsp70 stress proteins and did not cross-react with bovine serum albumin, foetal calf serum or $E$. coli lipopolysaccharide (data not shown). The detection limit of the assay was $0.1 \mathrm{ng} / \mathrm{ml} \mathrm{Hsp27}$, and the linear range was between 1 and $50 \mathrm{ng} / \mathrm{ml} \mathrm{Hsp} 27$ (Fig. 3). The intra- and inter-coefficients of variability were less than $7 \%$. The assay showed almost linear dilution of serum samples with PBS. The recovery rate of exogenously added recombinant Hsp27 to serum from donors with low $(1 \mathrm{ng} / \mathrm{ml})$ or medium levels $(15 \mathrm{ng} / \mathrm{ml})$ of endogenous Hsp27 was $\geq 95 \%$.

\section{Hsp60 measurement}

Hsp60 was measured by ELISA as previously described (Shamaei-Tousi et al. 2006) with few modifications. Hsp60 in serum or recombinant Hsp60 protein (ATgen; $0-5 \mu \mathrm{g} / \mathrm{ml}$ ) was captured with a mouse monoclonal anti-Hsp60 antibody (clone LK1, Stressgen; $1 \mu \mathrm{g} / \mathrm{ml}$ ). A goat polyclonal antiHsp60 antibody (Stressgen; $1 \mu \mathrm{g} / \mathrm{ml}$ ) was used as detection antibody, followed by incubation with a biotinylated donkey polyclonal anti-goat IgG (Alpha Diagnostics, 1:5000). Bound secondary antibody was detected with Streptavidin-HRP (Biolegend; $0.25 \mu \mathrm{g} / \mathrm{ml}$ ). The assay was developed with TMB substrate (affymetrix/eBioscience), and the reaction stopped with $2 \mathrm{~N} \mathrm{H}_{2} \mathrm{SO}_{4}$.

\section{Cytokine measurements}

Serum levels of IL- $1 \beta$, IL-6, IL-10 and TNF- $\alpha$ were measured by two-site ELISA using commercial kits according to the manufacturer's recommendations (Human Ready-SET-Go!® ELISA, affymetrix/eBioscience).

\section{Statistical analysis}

Since no data on Hsp27 relative to periodontal disease are available in the literature, no formal sample size calculation was performed. All data were analysed using SPSS Statistics software package (V24, IBM). Differences in the characteristics between the case-control study groups were computed 
with parametric (independent-samples $t$ test) or nonparametric (Mann-Whitney U Test) tests dependent upon the data frequency distribution and equality and homogeneity of variance tests. Categorical variables were analysed by chisquare testing. Because the distribution of heat-shock protein and cytokine concentrations in blood was markedly skewed, data was natural log-transformed (LN) (after adding a constant) to achieve a more normal distribution prior to statistical analysis. Differences in analyte concentrations between subject groups were analysed by parametric independent-samples $t$ tests or one-way between-group (ANOVA) tests followed by a post hoc comparison using the Tukey HSD test. Parametric correlation analysis (Pearson) was performed to evaluate the association between cytokine and heat-shock protein concentrations in serum. Age, gender, BMI and cigarette smoking were included in all models as covariates. A two-sided value of $p<0.05$ was considered statistically significant.

\section{Results}

\section{Case-control-study}

The main characteristics of $\mathrm{AgP}$ and $\mathrm{CP}$ patients and healthy controls are reported in Table 1. Baseline concentrations of systemic levels of the pro-inflammatory cytokines IL-1, IL-6 and TNF- $\alpha$ and the anti-inflammatory cytokine IL-10 were compared between healthy subjects and patients diagnosed with $\mathrm{AgP}$ or CP (Fig. 2). There was no statistically significant difference in the cytokine levels between the three groups for IL-1 ( $p=0.078$; Kruskal-Wallis test), IL-6 ( $p=0.39$; ANOVA) and IL-10 ( $p=0.93$; ANOVA). TNF- $\alpha$ levels were reduced in $\mathrm{AgP}$ patients ( $p=0.02$; ANOVA).

Hsp60 serum concentrations were not significantly different ( $p=0.172$, one-way ANOVA) between healthy individuals and patients with periodontitis (Fig. 3). The analysis of Hsp27 concentrations in the serum of $\mathrm{H}, \mathrm{AgP}$ or $\mathrm{CP}$ patients revealed a statistically significant difference between the three subject groups (one-way ANOVA, $p<0.001$ ) (Fig. 4). Post hoc tests (Tukey HSD) indicated that patients diagnosed with AgP had significantly less Hsp27 $(\mathrm{M}=0.62, \mathrm{SD}=0.97)$ in their circulation than healthy subjects $(\mathrm{M}=1.68, \mathrm{SD}=0.97)$ or $\mathrm{CP}$ patients $(\mathrm{M}=1.59, \mathrm{SD}=0.84)$. We further analysed the effect of possible known confounding factors (age, gender, BMI, smoking, and PPD $>4 \mathrm{~mm}$ ) on Hsp27 levels. Standard multiple regression analysis identified smoking as a confounding factor for Hsp27 serum levels $(p=0.004)$. However, after adjustment for smoking, age, gender, BMI and number of PPD, the detected association between $\mathrm{AgP}$ and Hsp27 levels remained statistically significant (ANCOVA, $p=0.013$ ).

The relationship between serum concentrations of systemic stress proteins (Hsp27, Hsp60) and cytokines (IL-1, IL-6, $\mathrm{TNF}-\alpha, \mathrm{IL}-10$ ) in healthy individuals and $\mathrm{CP}$ or $\mathrm{AgP}$ patients
Table 1 Comparison of demographic characteristics, clinical parameters and serum baseline measurements of patients and control subjects

\begin{tabular}{llllr}
\hline & AgP & CP & H & $p$ value \\
\hline Cases [n] & 30 & 29 & 28 & \\
Age [years] & $35.5(5.0)$ & $42.2(8.2)$ & $39.4(11.2)$ & 0.011 \\
Male gender [\%] & 30 & 37.9 & 32.1 & 0.801 \\
Smokers current [\%] & 46.7 & 37.9 & 10.7 & 0.01 \\
BMI & $26.4(7.0)$ & $25.4(6.0)$ & $22.8(2.2)$ & 0.036 \\
Sites with PPD $>4$ mm [n] & $67.5(39.2)$ & $44.1(24.9)$ & 0 & $<0.001$ \\
IL-1 [pg/ml] & $7.9(107.8)$ & $13.4(247.3)$ & $16.9(122.1)$ & 0.078 \\
IL-6 [pg/ml] & $1.9(39.0)$ & $2.7(22.4)$ & $1.2(10.8)$ & 0.039 \\
TNF [pg/ml] & $2.4(104.6)$ & $7.8(192.2)$ & $6.9(37.4)$ & 0.02 \\
IL-10 [pg/ml] & $2.9(19.5)$ & $4.2(83.7)$ & $3.5(7.8)$ & 0.093 \\
Hsp60 [ng/ml] & $51.3(9088)$ & $136.7(10,000.0)$ & $90.3(3023.3)$ & 0.172 \\
Hsp27 [ng/ml] & $1.7(25.0)$ & $4.7(37.6)$ & $4.9(3.5)$ & $<0.001$ \\
\hline
\end{tabular}

The table shows the characteristics of subjects included in both studies. Continuous demographic and clinical variables (age, BMI and PPD) are reported as mean and standard deviation, serum analytes (IL-1, IL-6, TNF, IL-10, Hsp60, Hsp27) as median and interquartile range. The last column reports the statistical significance ( $p$ value) of the differences between the three groups. Categorical variables were analysed by chi-square test for independence. The differences for continuous variables were computed with parametric (one-way betweengroups ANOVA) or non-parametric (Kruskal-Wallis) tests dependent upon the data frequency distribution. Serum analyte data were transformed as described in the "Material and methods" section prior to statistical analysis

$A g P$ aggressive periodontitis, $C P$ chronic periodontitis, $H$ healthy subjects, $B M I$ body mass index, $P P D$ pocket probing depth 
Fig. 2 a-d Pro- and anti-inflammatory cytokine concentrations in the circulation were similar between healthy subjects and patients with different forms of periodontitis. Cytokine concentrations in serum of healthy subjects ( $\mathrm{H}, n=28)$ and patients diagnosed with periodontitis classified into aggressive periodontitis (AgP, $n=29$ ) and chronic periodontitis (ChP, $n=29)$. The concentrations of IL-1 (a), IL-6 (b), TNF- $\alpha$ (c) and IL-10 (d) were measured by two-site ELISA. The data distribution of transformed cytokine concentration is visualised as box-and-whisker plots (SPSS). The boxes represent the interquartile range and the line inside the box refers to the median value. The whiskers extend to the smallest and largest values within 1.5 times the interquartile range; outliers (as defined by SPSS) are visualised as open circles
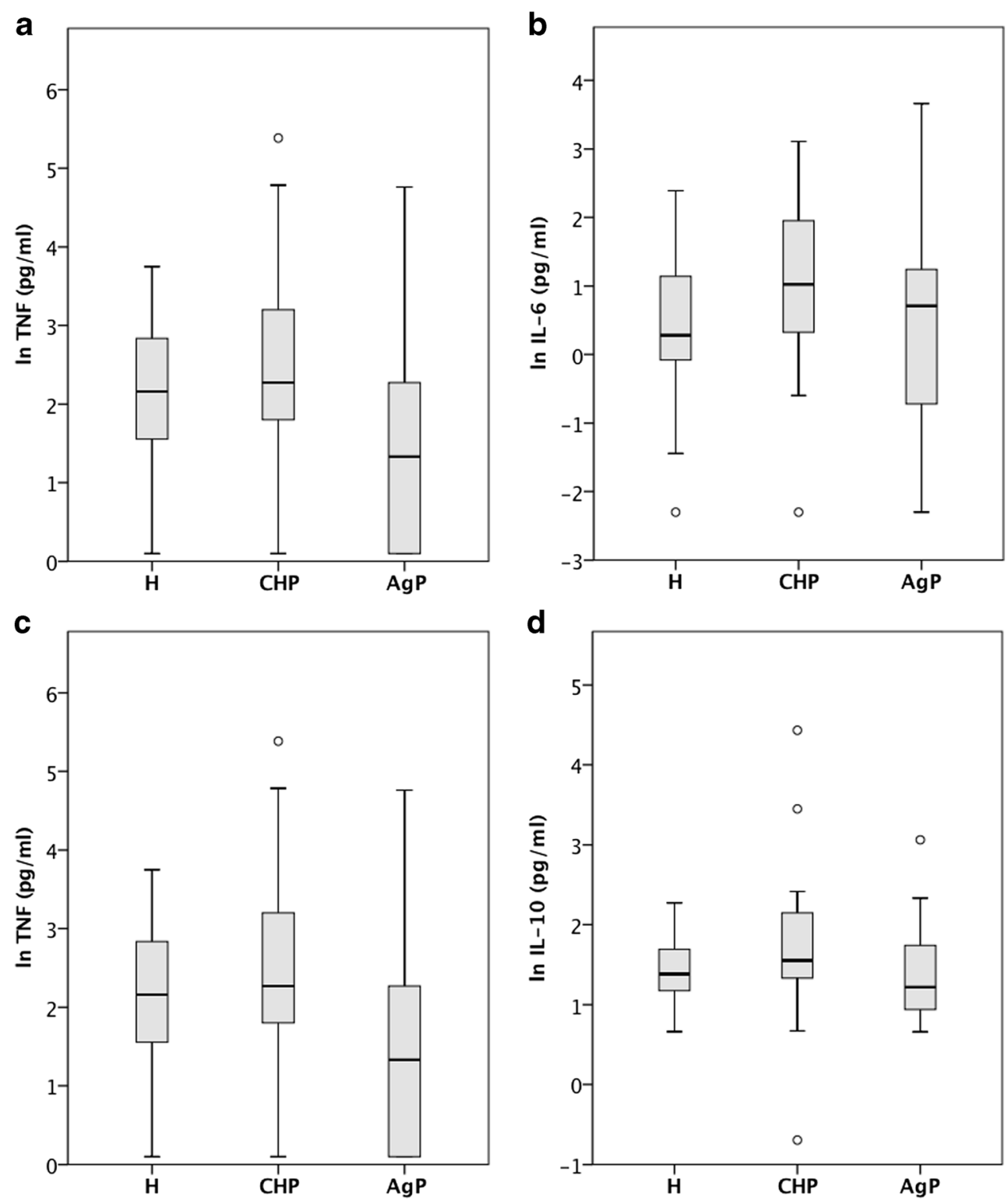

(Table 2) was investigated using Pearson correlation coefficient analyses. Preliminary analyses were performed to ensure no violation of the assumptions of normality, linearity and homoscedasticity. We observed complex patterns of positive associations which markedly differed across the subject groups. In both AgP and CP but not $\mathrm{H}$ subjects, strong associations between IL- 1 and IL-10 or TNF- $\alpha(r>0.52$, $p<0.01)$, as well as between IL-10 and TNF- $\alpha(r>0.47$, $p<0.01)$, were detected. The association patterns of Hsp60 were similar between the three subject groups: Hsp60 showed a strong positive association with both IL- 6 and TNF- $\alpha(r>0.53$, $p<0.01$ ), but only weak associations with IL-1 and IL-10 in all groups. In sharp contrast, Hsp27 levels were strongly associated with Hsp60 and TNF- $\alpha(r>0.43, p<0.01)$ in healthy individuals and $\mathrm{CP}$ patients, whereas no such associations could be revealed in $\mathrm{AgP}$ patients.

\section{Treatment study}

Hsp60 and Hsp27 serum levels were measured in patients with $\operatorname{AgP}(n=12)$ at various time points after induction of periodontal therapy (as described in the "Material and methods" section). The concentration of Hsp60 in the serum of these patients remained largely unchanged upon periodontal treatment (data not shown). In sharp contrast, these patients showed profound and highly dynamic changes in circulating Hsp27 levels after non-surgical (NSPT) and surgical (OFD) treatment (Fig. 5). However, the temporal patterns resulting from fluctuating Hsp27 levels after treatment were highly heterogeneous across AgP patients and no consistent direction or magnitude of Hsp27 response could be observed in the treatment time points investigated. 


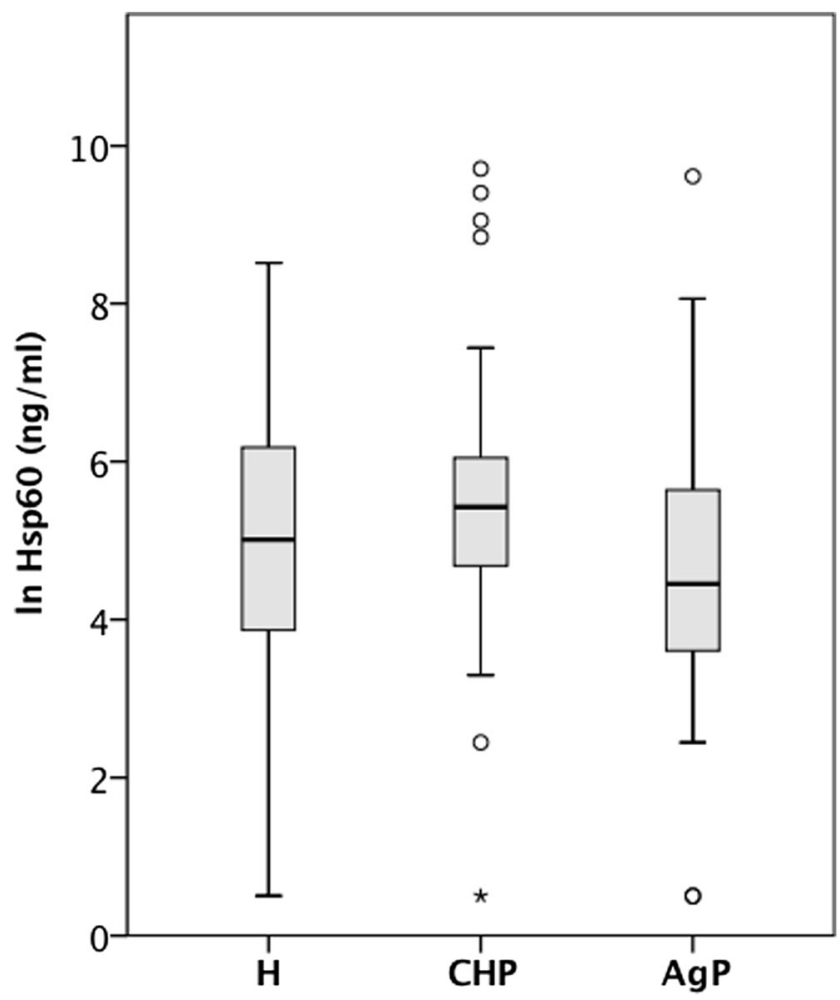

Fig. 3 Systemic levels of Hsp60 were similar in healthy individuals and patients with different forms of periodontitis. The concentration of Hsp60 in the serum was measured by two-site ELISA. The distribution of transformed Hsp60 concentrations in the serum of healthy subjects $(\mathrm{H}$, $n=28)$ and patients diagnosed with chronic (ChP, $n=29)$ or aggressive $(\mathrm{AgP}, n=30)$ periodontitis is visualised as box-and-whisker plots (SPSS)

\section{Discussion}

This study is the first to suggest that systemic concentrations of Hsp27 may differ between different types of periodontal disease. Periodontitis is characterised by the development of an exacerbated host inflammatory response leading to destruction of tooth-supporting hard and soft tissue and, ultimately, to tooth loss. Its prevalence is high and currently increasing in industrialised populations, with a recently increased prevalence of severe periodontitis up to nearly $10 \%$ (Eke et al. 2012). Based on recent surveys, approximately half of the US and half of the UK population suffer from periodontitis (Eke et al. 2012). Periodontitis is heterogeneous and currently classified into two main forms: chronic periodontitis (CP) and the rarer aggressive periodontitis $(\mathrm{AgP})$ which is estimated to affect approximately 1-2\% of individuals (Albandar and Tinoco 2002). AgP usually affects younger systemically healthy individuals and has a more rapid rate of progression. However, there is currently no objective biomarker-based diagnostic tool or sufficiently distinct histopathological characteristics to discriminate the two forms of periodontitis (Armitage and Cullinan 2010), so the current classification is under revision.

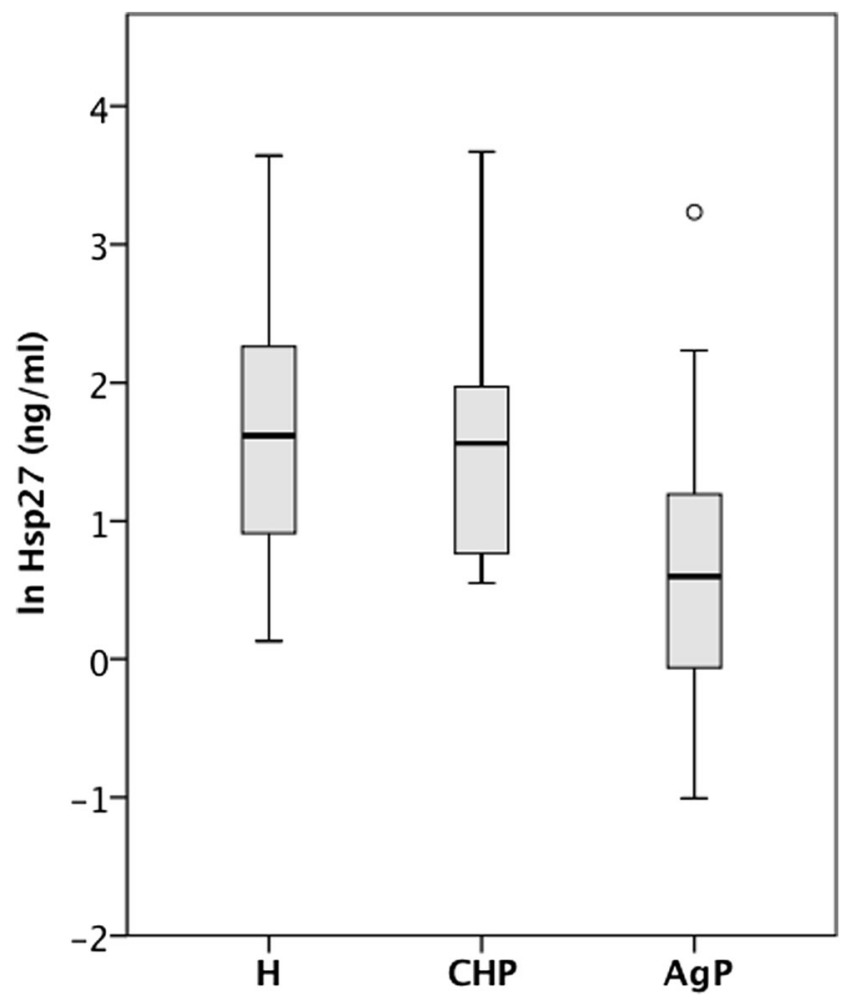

Fig. 4 Patients diagnosed with aggressive periodontitis had significantly lower levels of Hsp27 in their circulation. The concentration of Hsp27 in the serum of healthy donors $(n=28)$, patients with chronic $(n=29)$ or aggressive $(n=30)$ periodontitis, was measured by two-site ELISA. The box-and-whisker plot shows the distribution of Hsp27 concentrations after transformation

Molecular chaperones, also referred to as "cell stress proteins" or "heat shock proteins" (HSPs) - as their levels often increase during cell stress (such as elevated temperature), include a repertoire of functions such as de novo protein folding, disaggregation and protein trafficking. Initially, cell stress proteins were assumed to be purely intracellular proteins (Wick et al. 2004; Henderson and Pockley 2005). However, it has been demonstrated that in addition to their intracellular chaperoning functions, cell stress proteins can be released by cells and exist on the outer plasma membrane or in extracellular environments such as body fluids (Panayi et al. 2004). These secreted versions of cell stress proteins are found in the circulation in health and in a range of diseases and are increasingly being used as biomarkers in human disease states. Currently, we have most information about the role of circulating cell stress proteins in the cardiovascular diseases (Shamaei-Tousi et al. 2007b; Henderson and Pockley 2012) and in acute conditions like sepsis (Vardas et al. 2014, Briassouli et al. 2014). The secreted versions of stress proteins are hypothesised to have a broad spectrum of biological activities, depending on the particular protein and its concentration. Numerous studies have demonstrated that cell stress proteins have potent intercellular signalling actions for example with 
Table 2 Associations between circulating heat-shock proteins Hsp27 and Hsp60 and cytokines in healthy controls and patients with periodontitis

\begin{tabular}{lccccc}
\hline & Hsp27 & Hsp60 & IL-1 & IL-6 & IL-10 \\
\hline a. H & & & & & \\
Hsp60 & $0.599 * *$ & & & & \\
IL-1 & 0.059 & 0.177 & & & \\
IL-6 & 0.353 & $0.381 *$ & -0.132 & & \\
IL-10 & 0.09 & -0.118 & 0.058 & $0.562 * *$ & \\
TNF & $0.553 * *$ & $0.753 * *$ & 0.326 & 0.321 & 0.007 \\
$n$ & 28 & 28 & 28 & 27 & 27 \\
b. CP & & & & & \\
Hsp60 & $0.439 *$ & & & & \\
IL-1 & 0.254 & $0.377 *$ & & & \\
IL-6 & $0.446 *$ & $0.538 * *$ & 0.346 & & \\
IL-10 & 0.357 & $0.374 *$ & $0.525 * *$ & $0.453 *$ & \\
TNF & $0.482 * *$ & $0.672 * *$ & $0.545 * *$ & $0.453 *$ & $0.479 * *$ \\
$n$ & 29 & 29 & 29 & 29 & 29 \\
c. AgP & & & & & \\
Hsp60 & 0.33 & & & & \\
IL-1 & 0.084 & 0.343 & & & \\
IL-6 & -0.031 & $0.455^{*}$ & $0.637 * *$ & & \\
IL-10 & 0.064 & 0.313 & $0.632 * *$ & $0.620 * *$ & \\
TNF & 0.193 & $0.557 * *$ & $0.576 * *$ & $0.688 * *$ & $0.698 *$ \\
$n$ & 29 & 29 & 29 & 29 & 29 \\
\hline & & & & \\
\hline
\end{tabular}

The tables show the $R$ values of the parametric correlation analysis (Pearson) for serum levels of Hsp27, Hsp60 and cytokines IL-1, IL-6, IL-10 and TNF in (a) healthy subjects, (b) patients diagnosed with chronic periodontitis and (c) patients with aggressive periodontitis

Correlation is significant at the ${ }^{* *} p<0.01$ level (two-tailed); $* p<0.05$ level (two-tailed)

leukocytes and vascular endothelial cells, with activity profiles similar to those of pro- and anti-inflammatory cytokines (also referred to as "chaperokine" function) (Henderson and Pockley 2010). This suggests that cell stress proteins may function, like cytokines, as extracellular homeostatic control proteins or as homeostatic controllers of immunity (Henderson 2010; Henderson and Kaiser 2013). For example, the secreted pro-inflammatory cell stress protein cyclophilin A has been proposed as a therapeutic target in atherosclerosis (Bukrinsky et al. 2013) as well as a diagnostic maker for vascular disease in type 2 diabetes (Ramachandran and Kartha 2012). The heat-shock protein Hsp10 and the endoplasmic reticulum molecular chaperone BiP (HSPA8) have been demonstrated to have significant anti-inflammatory actions (Vanags et al. 2006; Panayi and Corrigall 2014) and both are currently undergoing clinical investigation. However, the role of other stress proteins such as Hsp72 is still less clear, with human studies showing either a protective role or an association with mortality and infections in sepsis (Briassoulis et al. 2014; Levada et al. 2018).
With regard to the role of secreted cell stress proteins in periodontitis, both bacterial and host heat-shock proteins are hypothesised to contribute to pathology. To date, only a few studies have investigated the potential role of circulating levels of human cell stress proteins in the periodontal disease pathogenesis (Nethravathy et al. 2014; Tsybikov et al. 2014). Notably, our group has demonstrated that circulating levels of Hsp10 and of BiP, both considered anti-inflammatory agents, were significantly higher in healthy controls than in patients with periodontitis, suggesting that these two cell stress proteins were either not being secreted or were being removed from the circulation in patients with periodontitis (Shamaei-Tousi et al. 2007a).

Hsp27 is a major intracellular molecular chaperone and controller of intracellular responses to inflammatory signals (Alford et al. 2007). Recombinant Hsp27 is also able to modulate myeloid cell activity with the protein showing an antiinflammatory mode of action in vitro (De et al. 2000). Furthermore, Hsp27 in the circulation has been demonstrated to function as an atheroprotective protein by preventing the release of inflammatory cytokines (Rayner et al. 2009; Józefowicz-Okonkwo et al. 2009). Hsp27 is also expressed in numerous human cancers, and its expression seems to correlate with poor clinical outcome (Ciocca and Calderwood 2005). In particular, treatments aimed at modulating Hsp27 levels and particularly its effects on apoptosis are being experimented on for prostate cancer treatment ( $\mathrm{Yu}$ et al. 2017). The role of systemic Hsp27 in periodontitis is currently unknown and we are not aware of any studies investigating it. Interestingly, the serum concentrations of key cytokines, typically involved in the induction and resolution of inflammatory processes, failed to distinguish between disease status or between the two forms of the disease, AgP and CP, respectively. Notably, we found that the concentration of Hsp27 in peripheral blood in AgP patients was significantly lower than in CP patients or in healthy controls. This finding suggests that in AgP patients, either less Hsp27 is being secreted or Hsp27 is being removed from the circulation at a greater than normal rate (Lebherz-Eichinger et al. 2012). In line with the described promotion of anti-inflammatory signalling by released Hsp27 (De et al. 2000; Rayner et al. 2008), the identified lower levels of this stress protein in the blood of AgP patients may result in impaired immune-dampening activity thereby contributing to an exacerbation of periodontal disease.

Our (Nibali et al. 2013) and other groups (Becerik et al. 2012; Mattuella et al. 2013) have previously investigated to which extent local and systemic levels of cytokines may contribute to the manifestation of severe periodontal disease. We have also proposed the hypothesis that cell stress proteins and cytokines generate complex intra- and extracellular networks, which function in the control of cells to external and internal stressors (Henderson and Kaiser 2013; Kaiser et al. 2014). The existence of such networks would suggest that the cell stress 


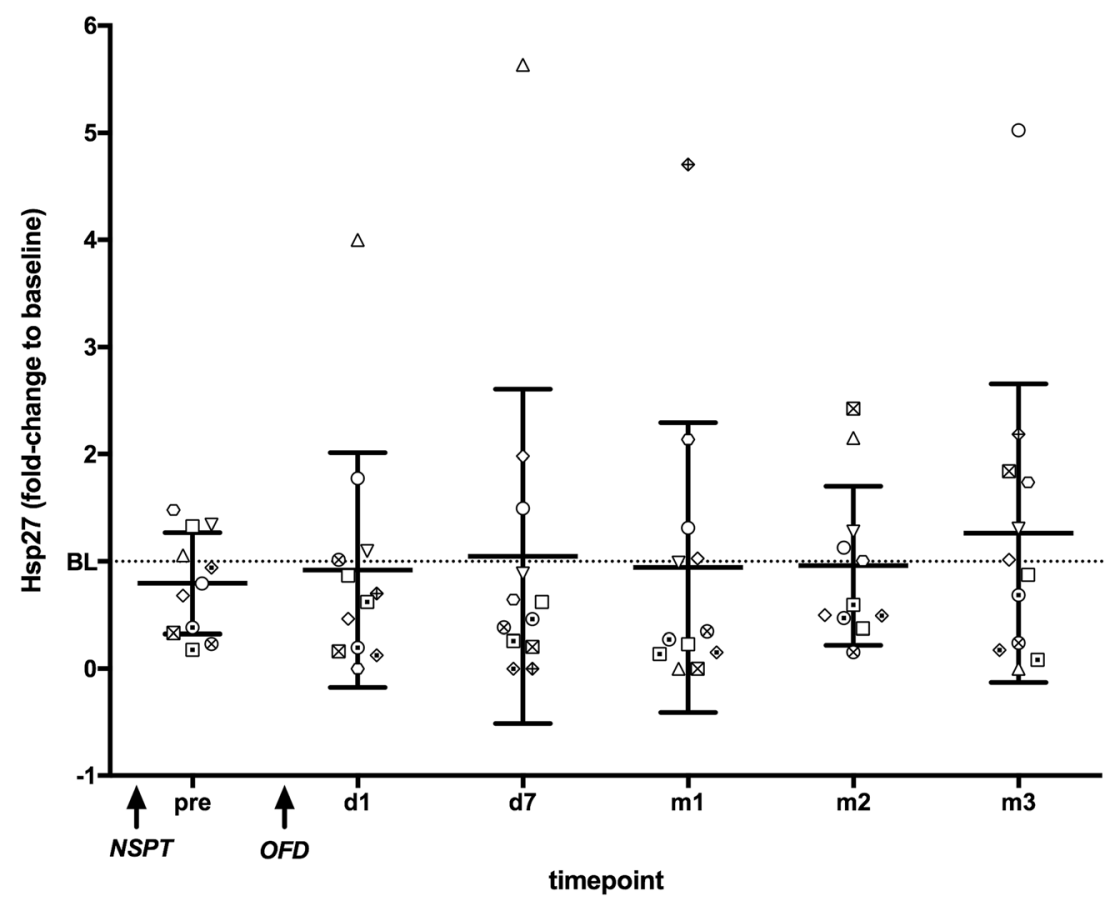

Fig. 5 Periodontal treatment in patients with aggressive periodontitis induces complex and dynamic changes of Hsp27 concentration in their circulation. The graph shows Hsp27 concentrations in the serum of 12 AgP patients who have undergone periodontal treatment. Hsp27 concentrations (fold-change) are shown over time as compared to

response is a key parameter in cytokine network generation and, as a consequence, in control of immunity. This raises the question whether the two heat-shock proteins investigated in this study, Hsp27 and Hsp60, may be part of a cell stress protein-cytokine network controlling inflammation in periodontal disease. Interestingly, when we analysed the association between circulating levels of Hsp27 and concentrations of key cytokines involved in the onset of inflammation (IL-1 $\beta$, IL-6, TNF- $\alpha$ ) as well as resolution of inflammation (IL-10), we detected distinct differences in the HSP-cytokine associations between healthy subjects, $\mathrm{CP}$ and $\mathrm{AgP}$ patients. While Hsp27 correlated positively with Hsp60, TNF- $\alpha$ and to a lesser extent IL-6 in both healthy subjects and CP patients, there were no associations for Hsp27 detectable in the $\mathrm{AgP}$ subgroup. In sharp contrast to the Hsp27-cytokine associations, Hsp60 concentrations correlated positively with IL-6 and IL-10 levels in all groups. These results support the hypothesis that highly complex HSP-cytokine networks control the inflammatory processes in periodontal diseases and emphasise that the composition or function of such networks may be different in clinically distinct forms of periodontitis.

Treatment of AgP patients resulted in significant changes in circulating hsp27 levels in all individuals. Interestingly, the temporal Hsp27 response patterns were highly dynamic, showing that its levels both increased and decreased by different magnitude after individual treatments. However, no clear pattern of change was observed across all treated cases. As no baseline (BL) Hsp27 levels determined in serum samples taken prior to periodontal treatment. Hsp27 was measured 6 weeks (pre) after nonsurgical periodontal treatment (NSPT) and 1 and 7 days (d) and 1, 2 and 3 months $(\mathrm{m})$ after periodontal surgery (OFD, open-flap debridement performed 2 months post-NSPT)

untreated controls were available for comparison, it is not clear whether the observed changes were due to periodontal treatment or were part of normal fluctuations of Hsp27 systemic concentrations.

The lack of associations between Hsp27 and cytokines suggests that this particular heat-shock protein may prospectively be investigated as a novel, possibly cytokine-independent, molecular regulator for the resolution of inflammation in periodontitis. One hypothesis is that stress proteins are interacting with pro-inflammatory target cells in an attempt to dampen their activity and control inflammation and, in essence, are being used up. However, it should be noted that the trauma and release of a huge burden of microbes from the gingival pockets upon treatment also has the potential to influence directly the expression and release of Hsp27 into the circulation. Further studies in large cohorts need to investigate systemic levels of heat-shock proteins after periodontal treatment (Shamaei-Tousi et al. 2007a).

Limitations of this study include absence of untreated controls in the treatment part, absence of investigation of local (oral or subgingival) Hsp27 levels and a relatively limited sample size. The strengths lie in the analysis of a range of periodontal phenotypes (healthy, AgP, CP) and a range of cytokines and heat-shock proteins, including the novelty of Hsp27 analysis. Our finding that the concentration of Hsp27 in the serum of patients with periodontitis significantly differs between distinct forms of the disease suggests that this protein may be 
differently regulated in different forms of periodontitis. This finding should be investigated in independent larger populations, should be extended to other HSPs and should include analysis of local/intracellular HSP levels, before the possible pathogenic effect of Hsp27 and its potential to serve as a biomarker for clinical purposes are considered.

Open Access This article is distributed under the terms of the Creative Commons Attribution 4.0 International License (http:// creativecommons.org/licenses/by/4.0/), which permits unrestricted use, distribution, and reproduction in any medium, provided you give appropriate credit to the original author(s) and the source, provide a link to the Creative Commons license, and indicate if changes were made.

\section{References}

Albandar JM, Tinoco EMB (2002) Global epidemiology of periodontal diseases in children and young persons. Periodontol 2000 29:153-176

Alford KA, Glennie S, Turrell BR et al (2007) Heat shock protein 27 functions in inflammatory gene expression and transforming growth factor-beta-activated kinase-1 (TAK1)-mediated signaling. J Biol Chem 282:6232-6241. https://doi.org/10.1074/jbc.M610987200

Armitage GC (2004) Periodontal diagnoses and classification of periodontal diseases. Periodontol 2000 34:9-21

Armitage GC (2010) Comparison of the microbiological features of chronic and aggressive periodontitis. Periodontol 2000 53:70-88. https://doi.org/10.1111/j.1600-0757.2010.00357.x

Armitage GC, Cullinan MP (2010) Comparison of the clinical features of chronic and aggressive periodontitis. Periodontol 2000 53:12-27. https://doi.org/10.1111/j.1600-0757.2010.00353.x

Becerik S, Öztürk VÖ, Atmaca H, Atilla G, Emingil G (2012) Gingival crevicular fluid and plasma acute-phase cytokine levels in different periodontal diseases. J Periodontol 83:1304-1313. https://doi.org/ 10.1902/jop.2012.110616

Briassouli E, Goukos D, Daikos G, Apostolou K, Routsi C, Nanas S, Briassoulis G (2014) Glutamine suppresses Hsp72 not Hsp90 $\alpha$ and is not inducing Th1, Th2, or Th17 cytokine responses in human septic PBMCs. Nutrition 30(10):1185-1194. https://doi.org/10. 1016/j.nut.2014.01.018

Briassoulis G, Briassouli E, Fitrolaki DM, Plati I, Apostolou K, Tavladaki T, Spanaki AM (2014) Heat shock protein 72 expressing stress in sepsis: unbridgeable gap between animal and human studies - a hypothetical "comparative" study. Biomed Res Int 2014:101023-101017. https://doi.org/10.1155/2014/101023

Bukrinsky M, Orekhov A, Ditiatkovski M, Sviridov D (2013) Cyclophilins in atherosclerosis: a new therapeutic target? Curr Pharm Des 19:5904-5908

Cairo F, Nieri M, Gori AM, Tonelli P, Branchi R, Castellani S, Abbate R, Pini-Prato GP (2010) Markers of systemic inflammation in periodontal patients: chronic versus aggressive periodontitis. An explorative cross-sectional study. Eur J Oral Implantol 3:147-153

Ciocca DR, Calderwood SK (2005) Heat shock proteins in cancer: diagnostic, prognostic, predictive, and treatment implications. Cell Stress Chaperones 10:86-103

De AK, Kodys KM, Yeh BS, Miller-Graziano C (2000) Exaggerated human monocyte IL-10 concomitant to minimal TNF-alpha induction by heat-shock protein 27 (Hsp27) suggests Hsp27 is primarily an antiinflammatory stimulus. J Immunol 165:3951-3958
Eke PI, Dye BA, Wei L, Thornton-Evans GO, Genco RJ, CDC Periodontal Disease Surveillance workgroup: James Beck (University of North Carolina, Chapel Hill, USA), Gordon Douglass (Past President, American Academy of Periodontology), Roy Page (University of Washin) (2012) Prevalence of periodontitis in adults in the United States: 2009 and 2010. J Dent Res 91:914-920. https://doi.org/10.1177/0022034512457373

Frydman A, Simonian K (2011) Aggressive periodontitis: the historic quest for understanding. J Calif Dent Assoc 39:377-382

Guerrero A, Griffiths GS, Nibali L, Suvan J, Moles DR, Laurell L, Tonetti MS (2005) Adjunctive benefits of systemic amoxicillin and metronidazole in non-surgical treatment of generalized aggressive periodontitis: a randomized placebo-controlled clinical trial. J Clin Periodontol 32:1096-1107. https://doi.org/10.1111/j.1600-051X. 2005.00814.x

Henderson B (2010) Integrating the cell stress response: a new view of molecular chaperones as immunological and physiological homeostatic regulators. Cell Biochem Funct 28:1-14. https://doi.org/10. 1002/cbf. 1609

Henderson B, Kaiser F (2013) Do reciprocal interactions between cell stress proteins and cytokines create a new intra-/extra-cellular signalling nexus? Cell Stress Chaperones 18:685-701. https://doi.org/ 10.1007/s12192-013-0444-9

Henderson B, Pockley AG (2005) Molecular chaperones and cell signalling. Cambridge University Press. Cambridge, UK

Henderson B, Pockley AG (2010) Molecular chaperones and proteinfolding catalysts as intercellular signaling regulators in immunity and inflammation. J Leukoc Biol 88:1-18. https://doi.org/10.1189/ jlb.1209779

Henderson B, Pockley AG (2012) Proteotoxic stress and circulating cell stress proteins in the cardiovascular diseases. Cell Stress Chaperones 17:303-311. https://doi.org/10.1007/s12192-011-0318-y

Jovaisaite V, Mouchiroud L, Auwerx J (2014) The mitochondrial unfolded protein response, a conserved stress response pathway with implications in health and disease. J Exp Biol 217:137-143. https://doi. org/10.1242/jeb.090738

Józefowicz-Okonkwo G, Wierzbowska-Drabik K, Kasielski M, Trzos E, Goraca A, Nowak D, Kasprzak J, Krzemińska-Pakuła M (2009) Is Hsp27 a marker of myocardial ischaemia? Kardiol Pol 67:947-952

Kaiser F, Steptoe A, Thompson S, Henderson B (2014) Monocyte cytokine synthesis in response to extracellular cell stress proteins suggests these proteins exhibit network behaviour. Cell Stress Chaperones 19:135-144. https://doi.org/10.1007/s12192-0130440-0

Kebschull M, Guarnieri P, Demmer RT, Boulesteix AL, Pavlidis P, Papapanou PN (2013) Molecular differences between chronic and aggressive periodontitis. J Dent Res 92:1081-1088. https://doi.org/ 10.1177/0022034513506011

Laudanski K, De A, Miller-Graziano C (2007) Exogenous heat shock protein 27 uniquely blocks differentiation of monocytes to dendritic cells. Eur J Immunol 37:2812-2824. https://doi.org/10.1002/eji. 200636993

Lebherz-Eichinger D, Ankersmit HJ, Hacker S, Hetz H, Kimberger O, Schmidt EM, Reiter T, Hörl WH, Haas M, Krenn CG, Roth GA (2012) HSP27 and HSP70 serum and urine levels in patients suffering from chronic kidney disease. Clin Chim Acta 413:282-286. https://doi.org/10.1016/j.cca.2011.10.010

Levada K, Guldiken N, Zhang X, et al. (2018) Hsp72 protects against liver injury via attenuation of hepatocellular death, oxidative stress, and JNK signaling. J Hepatol. doi: https://doi.org/10.1016/j.jhep. 2018.01.003.

Mattuella LG, Campagnaro MB, Vargas AE, Xavier LL, Oppermann RV, Chies JAB, Miranda LA (2013) Plasma cytokines levels in aggressive and chronic periodontitis. Acta Odontol Scand 71:683-688. https://doi.org/10.3109/00016357.2012.715191 
Mischak H, Ioannidis JPA, Argiles A, Attwood TK, Bongcam-Rudloff E, Broenstrup M, Charonis A, Chrousos GP, Delles C, Dominiczak A, Dylag T, Ehrich J, Egido J, Findeisen P, Jankowski J, Johnson RW, Julien BA, Lankisch T, Leung HY, Maahs D, Magni F, Manns MP, Manolis E, Mayer G, Navis G, Novak J, Ortiz A, Persson F, Peter K, Riese HH, Rossing P, Sattar N, Spasovski G, Thongboonkerd V, Vanholder R, Schanstra JP, Vlahou A (2012) Implementation of proteomic biomarkers: making it work. Eur J Clin Investig 42:1027-1036. https://doi.org/10.1111/j.1365-2362.2012.02674.x

Mombelli A, Casagni F, Madianos PN (2002) Can presence or absence of periodontal pathogens distinguish between subjects with chronic and aggressive periodontitis? A systematic review. J Clin Periodontol 29(Suppl 3):10-21-8

Nethravathy RR, Alamelu S, Arun K, Kumar T (2014) Evaluation of circulatory and salivary levels of heat shock protein 60 in periodontal health and disease. Indian J Dent Res 25:300-304. https://doi. org/10.4103/0970-9290.138317

Nibali L, Pelekos G, D'Aiuto F, Chaudhary N, Habeeb R, Ready D, Parkar M, Donos N (2013) Influence of IL-6 haplotypes on clinical and inflammatory response in aggressive periodontitis. Clin Oral Investig 17:1235-1242. https://doi.org/10.1007/s00784-012-0804-3

Panayi GS, Corrigall VM (2014) Immunoglobulin heavy-chain-binding protein $(\mathrm{BiP})$ : a stress protein that has the potential to be a novel therapy for rheumatoid arthritis. Biochem Soc Trans 42:1752-1755. https://doi.org/10.1042/BST20140230

Panayi GS, Corrigall VM, Henderson B (2004) Stress cytokines: pivotal proteins in immune regulatory networks. OpinCurr Opin Immunol 16(4):531-534. https://doi.org/10.1016/j.coi.2004.05.017

Papadopoulos P, Pistiki A, Theodorakopoulou M, Christodoulopoulou T, Damoraki G, Goukos D, Briassouli E, Dimopoulou I, Armaganidis A, Nanas S, Briassoulis G, Tsiodras S (2017) Immunoparalysis: clinical and immunological associations in SIRS and severe sepsis patients. Cytokine 92:83-92. https://doi.org/10.1016/j.cyto.2017. 01.012 .

Pockley AG, Henderson B (2018) Extracellular cell stress (heat shock) proteins - immune responses and disease: an overview. Philos Trans R Soc B Biol Sci 373:20160522. https://doi.org/10.1098/rstb.2016. 0522

Ramachandran S, Kartha CC (2012) Cyclophilin-a: a potential screening marker for vascular disease in type-2 diabetes. Can J Physiol Pharmacol 90:1005-1015. https://doi.org/10.1139/y2012-038

Rayner K, Chen Y-X, McNulty M, Simard T, Zhao X, Wells DJ, de Belleroche J, O'Brien ER (2008) Extracellular release of the atheroprotective heat shock protein 27 is mediated by estrogen and competitively inhibits acLDL binding to scavenger receptor-a. Circ Res 103:133-141. https://doi.org/10.1161/ CIRCRESAHA.108.172155

Rayner K, Sun J, Chen Y-X, McNulty M, Simard T, Zhao X, Wells DJ, de Belleroche J, O'Brien ER (2009) Heat shock protein 27 protects against atherogenesis via an estrogen-dependent mechanism: role of selective estrogen receptor beta modulation. Arterioscler Thromb Vasc Biol 29:1751-1756. https://doi.org/10.1161/ ATVBAHA.109.193656

Saibil H (2013) Chaperone machines for protein folding, unfolding and disaggregation. Nat Rev Mol Cell Biol 14:630-642. https://doi.org/ $10.1038 /$ nrm 3658
Shamaei-Tousi A, Stephens JW, Bin R, Cooper JA, Steptoe A, Coates ARM, Henderson B, Humphries SE (2006) Association between plasma levels of heat shock protein 60 and cardiovascular disease in patients with diabetes mellitus. Eur Heart J 27:1565-1570. https://doi.org/10.1093/eurheartj/eh1081

Shamaei-Tousi A, D'Aiuto F, Nibali L et al (2007a) Differential regulation of circulating levels of molecular chaperones in patients undergoing treatment for periodontal disease. PLoS One 2:e1198. https:// doi.org/10.1371/journal.pone.0001198

Shamaei-Tousi A, Halcox JP, Henderson B (2007b) Stressing the obvious? Cell stress and cell stress proteins in cardiovascular disease. Cardiovasc Res 74:19-28. https://doi.org/10.1016/j.cardiores.2006. 10.025

Smith M, Seymour GJ, Cullinan MP (2010) Histopathological features of chronic and aggressive periodontitis. Periodontol 2000 53:45-54. https://doi.org/10.1111/j.1600-0757.2010.00354.x

Spanaki AM, Tavladaki T, Dimitriou H, et al. (2018) Longitudinal profiles of metabolism and bioenergetics associated with innate immune hormonal inflammatory responses and amino-acid kinetics in severe sepsis and systemic inflammatory response syndrome in children. JPEN J Parenter Enteral Nutr. 2018. doi: https://doi.org/10. 1002/jpen. 1050

Tsybikov NN, Baranov SV, Kuznik BI, Malezhik LP, Isakova NV (2014) Serum, oral and gingival fluid levels of heat shock protein-70, cytokines and their autoantibodies by periodontal disease. Stomatol (Mosk) 93:16-18

Vanags D, Williams B, Johnson B, Hall S, Nash P, Taylor A, Weiss J, Feeney D (2006) Therapeutic efficacy and safety of chaperonin 10 in patients with rheumatoid arthritis: a double-blind randomised trial. Lancet (London, England) 368:855-863. https://doi.org/10.1016/ S0140-6736(06)69210-6

Vardas K, Apostolou K, Briassouli E, Goukos D, Psarra K, Botoula E, Tsagarakis S, Magira E, Routsi C, Nanas S, Briassoulis G (2014) Early response roles for prolactin cortisol and circulating and cellular levels of heat shock proteins 72 and $90 \alpha$ in severe sepsis and SIRS. Biomed Res Int 2014:803561. https://doi.org/10.1155/2014/ 803561

Vardas K, Ilia S, Sertedaki A, Charmandari E, Briassouli E, Goukos D, Apostolou K, Psarra K, Botoula E, Tsagarakis S, Magira E, Routsi C, Stratakis CA, Nanas S, Briassoulis G (2017) Increased glucocorticoid receptor expression in sepsis is related to heat shock proteins, cytokines, and cortisol and is associated with increased mortality. Intensive Care Med Exp 5(1):10. https://doi.org/10.1186/s40635017-0123-8.

Wang W-A, Groenendyk J, Michalak M (2014) Endoplasmic reticulum stress associated responses in cancer. Biochim Biophys Acta 1843: 2143-2149. https://doi.org/10.1016/j.bbamcr.2014.01.012

Wick G, Knoflach M, Xu Q (2004) Autoimmune and inflammatory mechanisms in atherosclerosis. Annu Rev Immunol 22:361-403. https://doi.org/10.1146/annurev.immunol.22.012703.104644

Yu EY, Ellard SL, Hotte SJ, Gingerich JR, Joshua AM, Gleave ME, Chi KN (2017) A randomized phase 2 study of a HSP27 targeting antisense, apatorsen with prednisone versus prednisone alone, in patients with metastatic castration resistant prostate cancer. Investig New Drugs. https://doi.org/10.1007/s10637-017-0553-x 